\title{
How good is grid coding versus place coding for navigation using noisy, spiking neurons?
}

\author{
Alexander Mathis ${ }^{1,2,3}$, Martin Stemmler ${ }^{1,2}$, Andreas Herz ${ }^{1,2^{*}}$ \\ From Nineteenth Annual Computational Neuroscience Meeting: CNS*2010 \\ San Antonio, TX, USA. 24-30 July 2010
}

Our understanding of how the brain encodes navigation through space underwent a revolution with the remarkable discovery of grid cells in the medial entorhinal cortex (MEC) of rodents [3]. A grid cell builds a hexagonal lattice representation of physical space, such that the cell fires whenever the rodent moves through a lattice point. In contrast, place cells in the hippocampus proper fire only at a single, specific location in space.

Different place cells encode different spatial locations, while different grid cells exhibit different lattice spacings, orientations, and phases. At the level of a single neuron, the multiple firing fields of a grid cell lead to an inherent ambiguity in the position estimate. Hence, for both codes precise information about position can only be gained from a population of grid and place cells respectively. We will present two different interpretations of the grid population code, one as an effective way of subdividing space with a high resolution and one based on modular arithmetic, similar to Fiete et.al. [2]. For a clarification of these concepts look at Figs 1 and 2 and in the appendix. We furthermore argue that the modular arithmetic interpretation is lacking robustness in both: capacity and resolution.

After these interpretations we set out to investigate the spatial resolution of the place code and the grid code on a limited, one-dimensional space with a finite amount of cells and families of tuning curves. Therefore, we built a stochastic population coding model as in Bethge [1]. The family of tuning curves convert the position into firing rates for statistically independent Poisson neurons. To compare the two coding schemes we calculate the maximum likelihood position estimate and compute the mean square error of the population code. We believe that the grid and place code should enable real-time readout of the rat's position while it is

Division of Neurobiology, Ludwig-Maximilians-Universität München, 82152 Planegg-Martinsried, Germany
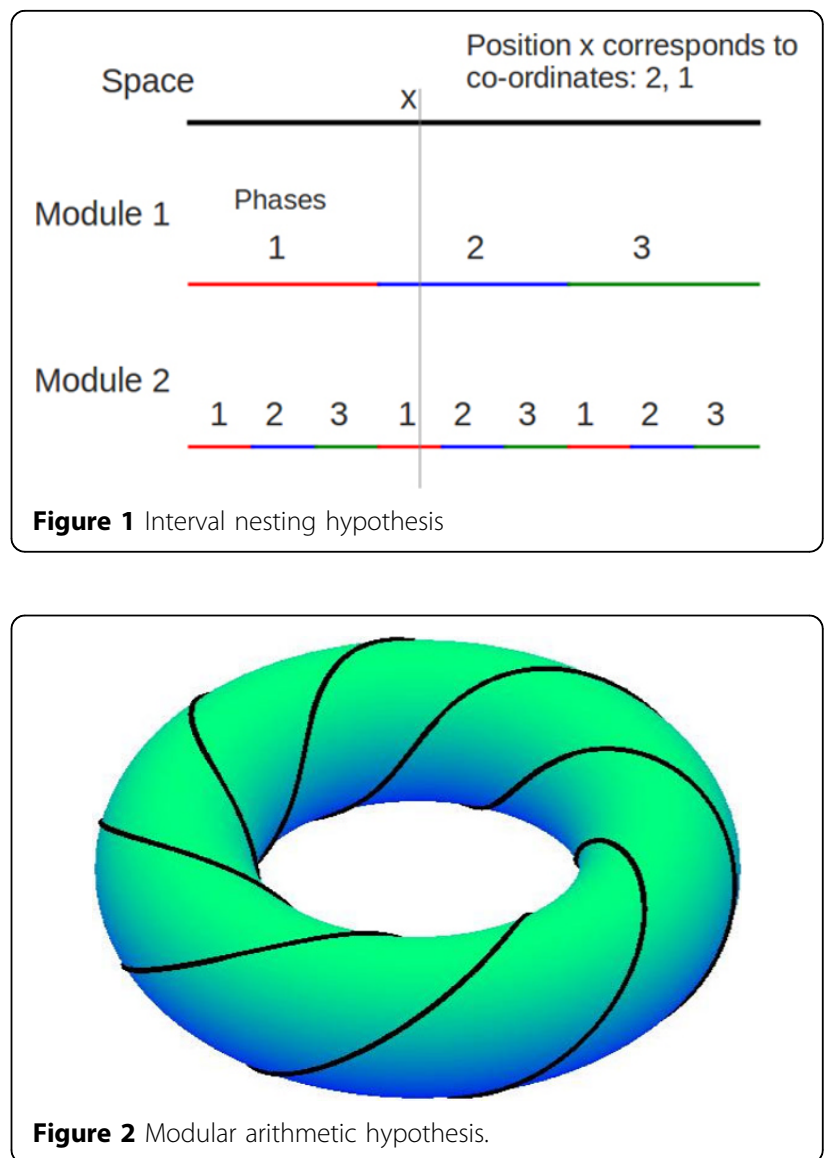

moving. For this reason, we have to consider short decoding times and hence, since Fisher information methods based on the Cramér Rao bound fail to estimate the mean error in such cases [1], we make use of Monte Carlo integration methods.

Under the condition of noisy, spiking neurons, we demonstrate that the grid code, if it is organized as in the interval nesting hypothesis outperforms the place 
code for any tuning width. On the other hand, if it is organized as in the modular arithmetic hypothesis, i.e. spatial periods that are far shorter than the length of space the grid code has a lower distortion than the best place codes.

\section{Author details}

'Division of Neurobiology, Ludwig-Maximilians-Universität München, 82152 Planegg-Martinsried, Germany . ${ }^{2}$ Bernsteincenter for Computational

Neuroscience Munich, University, 82152 Planegg-Martinsried, Germany .

${ }^{3}$ Graduate School for Systemic Neuroscience, LMU Munich, 82152 Planegg-

Martinsried, Germany.

Published: 20 July 2010

\section{References}

1. Bethge $M$, Rotermund $D$, Pawelzik K: Optimal short-term population coding: When Fisher information fails. Neural Computation 2002, 14(10):2317-2351.

2. Fiete IR, Burak $Y$, Brookings $T$ : What grid cells convey about rat location? J. Neurosci 2008, 28:6858-6871.

3. Hafting T, Fyhn M, Molden S, Moser MB, Moser El: Microstructure of a spatial map in the entorhinal cortex. Nature 2005, 436(7052):801-806.

doi:10.1186/1471-2202-11-S1-O20

Cite this article as: Mathis et al: How good is grid coding versus place coding for navigation using noisy, spiking neurons?. BMC Neuroscience 2010 11(Suppl 1):020.

\section{Submit your next manuscript to BioMed Central} and take full advantage of:

- Convenient online submission

- Thorough peer review

- No space constraints or color figure charges

- Immediate publication on acceptance

- Inclusion in PubMed, CAS, Scopus and Google Scholar

- Research which is freely available for redistribution

Submit your manuscript at www.biomedcentral.com/submit 